Original Research Article

\title{
A critical evaluation of information in drug promotional brochures for validity as per WHO criteria
}

\author{
Navyug R. Singh ${ }^{1 *}$, Gurpreet K. Randhawa ${ }^{1}$, Resham Kashyap ${ }^{2}$, Gobindnoor Kaur ${ }^{3}$
}

${ }^{1}$ Department of Pharmacology, Government Medical College, Amritsar 143001, Punjab, India ${ }^{2}$ Medical Advisor, Global India Generics, Dr Reddy's Lab Ltd., Ammerpet, Hyderabad 500038, Telangana, India ${ }^{3}$ Drug Safety Physician, Pharmacovigilance Parexel International Services India Private Ltd., Chandigarh 160101, India

Received: 24 March 2017 Accepted: 05 April 2017

*Correspondence to: Dr. Navyug R. Singh, Email: navyug69@gmail.com

Copyright: (C) the author(s), publisher and licensee Medip Academy. This is an openaccess article distributed under the terms of the Creative Commons Attribution NonCommercial License, which permits unrestricted noncommercial use, distribution, and reproduction in any medium, provided the original work is properly cited.

\begin{abstract}
Background: Promotion of drugs through publication of promotional literature is a standard practice of pharmaceutical companies. This study is aimed at critically analyzing the drug promotional brochures.

Methods: Observational study was conducted in Department of Pharmacology, Government Medical College Amritsar according to WHO guidelines. 100 brochures of different pharmaceutical companies were collected at random from various OPDs of a tertiary care hospital.

Results: Only $14 \%$ of total brochures demonstrated overall adherence to WHO guidelines. Safety information was lacking in $88 \%$. Irrelevant pictures were found in $66 \%$ brochures while relevant illustrated information was included in only $23 \%$ of brochures. Out of total illustrations found relevant $(n=44), 45.5 \%$ did not quote any reference, and results didn't match with original study in $11.4 \%$

Conclusions: Our study points towards big lacuna in drug promotional brochures, an important source of drug information. Low percentage of adherence to the guidelines in the study reflects commercial interest of pharmaceutical companies and lack of will to correctly disseminate the drug related information.
\end{abstract}

Keywords: Chart junks, Drug Controller General of India, Drug promotional literature, Data density index, Lie factor

\section{INTRODUCTION}

Pharmaceutical industry spends billions of dollars every year on promotion and marketing of medicinal products. Various promotion strategies include sponsorships, electronic and print media advertisements, medical representatives as well as drug promotion brochures. ${ }^{1}$ New drugs are growing exponentially in the market and keeping pace with them is difficult for busy physicians. The 'drug promotion brochures' form a major source of information regarding newer drugs in such a scenario and influence the prescribing behavior of the prescribers. ${ }^{2-5}$

World Health Organization (WHO) defines drug promotion as "all informational and persuasive activities by manufacturers and distributors, the effect of which is to induce the prescription supply, purchase, and use of medicinal drugs". To regulate the information quality, WHO has framed certain guidelines under 'Ethical criteria of medicinal drug promotion' and encourages use of these guidelines for advertisements and promotions 
through consistent, truthful and right means. ${ }^{6}$ WHO guidelines are globally accepted and are also followed by Indian Federation of Pharmaceutical Manufacturers Association (IFPMA) and Organization of Pharmaceutical Producers of India (OPPI). In India, the promotional activities are regulated by OPPI under "OPPI code of pharmaceutical practices in India". 7

Some studies have claimed the drug advertisements to be unethical despite all the regulatory efforts. ${ }^{5,8,9}$ 'Direct to physician' marketing may influence the prescribing practices. It is the responsibility of a physician to follow ethical prescribing practices as well as critically evaluate the claims made in the drug promotional literature. Attractive visual displays and the data presentation may be misleading and biased. The accuracy, validity and authenticity of the data needs to be critically appraised and interpreted. ${ }^{10}$ Very few studies have been done to assess the quality and quantity of graphic/visual presentations of the data displayed in the promotional brochures. ${ }^{11}$ Present study strives to assess the current status of compliance by the pharmaceutical companies in the promotional brochures on the basis of WHO guidelines. The objective is to evaluate completeness of information on the drug promotion brochures based on WHO criteria and to assess the quality and quantity of data displayed as graphic illustrations on the brochures.

\section{METHODS}

This was a cross-sectional and observational study carried out in a tertiary care hospital in Punjab. A total of 100 drug promotional brochures of different pharmaceutical companies were collected randomly from outpatient departments (OPDs). Brochures promoting medicinal devices and equipments, orthopedic prosthesis, ayurvedic medicines, drug monographs and literature promoting more than two brands were excluded from the study.

All the brochures were evaluated based on the following parameters of WHO Ethical criteria of medicinal drug promotion: 6

- The name of the active ingredient(s) using either international nonproprietary names (INN) or the approved generic name of the drug

- $\quad$ The brand name

- Content of active ingredient(s) per dosage form or regimen

- Name of other ingredients known to cause problems

- $\quad$ Approved therapeutic uses

- Dosage form or regimen

- $\quad$ Side-effects and major adverse drug reactions

- Precautions, contra-indications and warnings

- Major interactions

- Name and address of manufacturer or distributor

- Reference to scientific literature as appropriate
All the parameters were individually studied and analyzed for every brochure. Mention of product price on the brochures, if any, was recorded as it forms important parameter to assess the cost benefit of the drug. All the brochures were also analyzed for illustrations whether relevant or irrelevant. Relevant illustrations either tabular or graphic were critically assessed to determine quality and quantity of information displayed and compared to the actual study quoted for validity. The graphics were subjected to various criteria for well-designed illustrations like internal and external consistency and graphical efficiency. These were examined for visual clarity, internal contradictions, consistency with text, redundancy, adequate portrayal of data, numerical distortions, chart junk (unnecessary and distracting items) and completeness (explanation of symbols, abbreviations, labels). ${ }^{12,13}$

We also calculated the Data Density Index (DDI) and the Lie Factor (LF). DDI is intended to describe the average information content of a square centimeter of graphic. LF tests the conformity of effect size shown graphically to the actual data (LF = Size of effect shown in graph / Size of effect in data). LF should lie between 0.95 and 1.05. ${ }^{12}$

\section{RESULTS}

Out of the 100 brochures collected, 66 were single drug promotions and 44 promoted the fixed drug combinations (FDCs). $70 \%$ of all promoted single drugs were Drug Controller General of India (DCGI) approved, 45\% were United States Food and Drug Administration (USFDA) approved and only 3\% were from WHO essential medicine list 2013 (EML). ${ }^{14,15}$ Of the FDCs, only $24 \%$ were DCGI approved, $13 \%$ were USFDA approved and none figured in WHO EML.

On the basis of WHO criteria, (Table 1) only $14 \%$ of the brochures fulfilled overall completeness and adherence to guidelines. Safety information like side effects and major ADRs, was lacking in $78 \%$ of the brochures. Precautions and warnings related to pregnant and lactating women or children were lacking in $75 \%$ of brochures. Major interactions, which have to be taken care of during prescription, were lacking in $80 \%$ of brochures. Manufacturer's name was mentioned in $94 \%$ of brochures but complete address was mentioned in only $54 \%$ of brochures. Cost of the product was mentioned in only $9 \%$ of brochures.

Pictures and graphics formed a substantial portion of all the brochures. Irrelevant illustrations including pictures and cartoons were observed in $66(66 \%)$ of brochures, and $23(23 \%)$ of brochures showed relevant graphic or tabular presentations.

Multiple illustrations were displayed in many of the brochures so that there was a total of 169 illustrations out of which 44 were found to be relevant while other 125 were irrelevant with no connection at all to the drug in 
question. Of the total 44 relevant illustrations, $68.2 \%$ were bar charts, $18.2 \%$ line graphs, $4.5 \%$ boxes and whisker plots and $9.1 \%$ were tables. Further analysis was done only for relevant illustrations $(n=44)$ (Table 2).

Table 1: Evaluation of drug promotion brochures as per WHO criteria $(n=100)$.

\begin{tabular}{|c|c|c|}
\hline $\begin{array}{l}\text { S. } \\
\text { No. }\end{array}$ & Parameter & $\begin{array}{l}\text { Percent brochures } \\
\text { mentioning } \\
\text { parameter }\end{array}$ \\
\hline 1. & $\begin{array}{l}\text { Name of the active } \\
\text { ingredient/generic }\end{array}$ & $98 \%$ \\
\hline 2. & Brand name & $100 \%$ \\
\hline 3. & $\begin{array}{l}\text { Amount of active } \\
\text { ingredient/dose }\end{array}$ & $93 \%$ \\
\hline 4. & $\begin{array}{l}\text { Adjuvant known to } \\
\text { cause problem }\end{array}$ & $0 \%$ \\
\hline 5. & Indications & $94 \%$ \\
\hline 6. & Dosage form & $93 \%$ \\
\hline 7. & Regimen & $49 \%$ \\
\hline 8. & $\begin{array}{l}\text { Safety info: S/E, major } \\
\text { ADR } \\
\text { - precautions, C/I, } \\
\text { warnings } \\
\text { - major interactions }\end{array}$ & $\begin{array}{l}22 \% \\
25 \% \\
20 \%\end{array}$ \\
\hline 9. & $\begin{array}{l}\text { Manufacturer's details: } \\
\text { name } \\
\text { - complete address }\end{array}$ & $\begin{array}{l}94 \% \\
54 \%\end{array}$ \\
\hline 10. & References & $64 \%$ \\
\hline 11. & Price & $9 \%$ \\
\hline
\end{tabular}

Details of the graphics like sample size (n), confidence interval (CI), p-value were mentioned in $25 \%, 13.6 \%$, $34.1 \%$ of graphics respectively. Study outcome were mainly disease oriented in $64 \%$ of graphics, of which quantitative outcome like efficacy (23/44, 52.3\%), relative risk reduction (RRR) $(9 / 44,20.5 \%)$, absolute risk reduction (ARR) $(0 \%)$ and number needed to treat $(\mathrm{NNT})$ $(0 \%)$ were mentioned. We observed univariate display of statistics. In all graphics, abbreviations, legends and titles were clearly defined making them self explanatory. In the analysis of graphic characteristics we found $4.5 \%$ discrepancies between the text and graphics, whereas no external redundancy of data was observed. Numeric distortions were seen in $13.5 \%$ of graphics. $54 \%$ graphics included either extraneous ink in the form of chart junk (Table 3). Among graphics, the mean difference observed in Lie factor was 6.56 (0.94-10.6). The DDI varied greatly depending on the graphic and the type of data analyzed in the study. For all the graphic types combined, the average DDI was 0.14 .

\section{DISCUSSION}

There is a severe lack of information in the promotional brochures, which reflects non adherence to the guidelines framed at national and international levels. Most vital information regarding drug safety like ADRs, precautions, drug interactions etc. was found missing in about $80 \%$ of the brochures.

Table 2: Analysis of pictures and graphics in brochures as per WHO criteria $(n=44)$.

\begin{tabular}{|ll|}
\hline Evaluation parameters & Number (Percent) \\
\hline Bar graphs & $30(68.2 \%)$ \\
\hline Line graphs & \multicolumn{1}{c|}{$8(18.2 \%)$} \\
\hline Boxes and whisker plots & $2(4.5 \%)$ \\
\hline Tables & $4(9.1 \%)$ \\
\hline Whether sample size mentioned & \\
\hline Yes & $11(25 \%)$ \\
\hline No & $33(75 \%)$ \\
\hline Whether Confidence Interval (CI) mentioned \\
\hline Yes & $6(13.6 \%)$ \\
\hline No & $38(86.4 \%)$ \\
\hline Whether p-value mentioned & $15(34.1 \%)$ \\
\hline Yes & $29(65.9 \%)$ \\
\hline No & $6(13.6 \%)$ \\
\hline Patient or disease oriented outcome mentioned \\
\hline Patient oriented & $28(63.6 \%)$ \\
\hline Disease oriented & $23(52.3 \%)$ \\
\hline Outcome parameters mentioned \\
\hline Efficacy & $9(20.5 \%)$ \\
\hline RRR (Relative Risk ratio) & $0(00 \%)$ \\
\hline ARR (Absolute Risk Ratio) & $0(00 \%)$ \\
\hline NNT (Number Needed to Treat) & $12(27.3 \%)$ \\
\hline Others & $5(11.4 \%)$ \\
\hline Whether data on brochure matched original study \\
\hline Data matched & $20(45.5 \%)$ \\
\hline Did not match & \\
\hline $\begin{array}{l}\text { No reference quoted/ study } \\
\text { inaccessible }\end{array}$ \\
\hline
\end{tabular}

Table 3: Analysis of graphic excellence in brochures as per WHO criteria $(n=44)$.

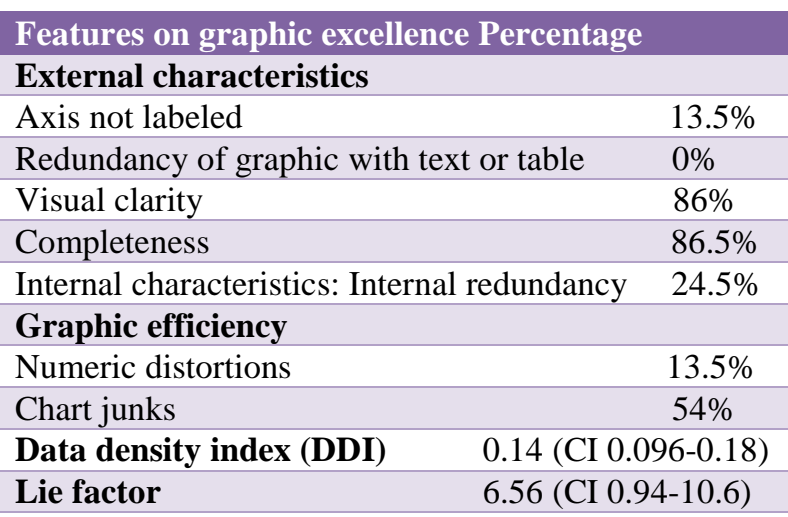

No information on dose adjustment in case of pregnancy, lactating mothers, children or elderly was mentioned in any of the analyzed brochures. Drug regimen was missing in $51 \%$ of brochures. Thus the Drug Promotion Brochures are found to be inconsistent in giving complete and valid information to the physicians. This finding is 
not only limited to India but has also been observed in studies conducted in other countries like Russia, Saudia and Australia. ${ }^{16-19}$ Thus it becomes necessary for a prescribing physician to be vigilant before relying on these informational brochures.

Another aspect of the study was focused on quantitative and qualitative estimation of information displayed on the brochures. Lot of space is wasted in advertising irrelevant pictures with an intention to make the promotion catchy and attractive. $66 \%$ of the brochures contained 125 irrelevant pictures which had no relation with the drug or its therapy. The relevant illustrations which reflected the claims and results of study outcomes were present in only $23 \%$ of brochures. Even in the illustrations found to be relevant, the data were simple and univariate displays. Cooper et al describes such displays to be of poor quality as they fail to convey the complexity and often distort the findings. ${ }^{13}$

Graphics are means of information exchange among professionals. The data presented should be clear and in detail so that the reader can critically evaluate the results and come up with his or her own conclusions. In our study, majority of graphics that were evaluated, were simple bar graphs showing mean difference or frequency. Parameters on study analysis like sample size was missing in $75 \%$. Confidence Interval and p-value were not mentioned in $86.4 \%$ and in $65.9 \%$ respectively.

Majority of the outcomes mentioned were diseaseoriented and not patient-oriented. It is important to present data which reflects morbidity, mortality or quality of life and change in these parameters with intervention. ${ }^{11}$ In our study, patient-oriented outcomes were seen in only $14 \%$ of brochures.

Quantitative outcomes reported were mainly efficacy and RRR. None of the brochures mentioned ARR or NNT. $\mathrm{RRR}$ is the percentage reduction in the risk of targeted complications between two comparison groups. It does not mention the baseline risk of the event; is known to reflect amplified results and may show even insignificant values as significant. An ARR is the absolute percentage difference in the risk of targeted complications between two groups. Its value is better related to the true difference between the comparison groups. NNT is number of patients that are needed to be treated to prevent one event. ${ }^{20}$ Studies have shown that physicians enthusiasm is more on how the results are presented hence the companies have more inclination towards mentioning of RRR as it shows exaggerated result outcomes and can easily manipulate the prescribing behavior. $^{21,22}$ Displaying RRR alone will distort the findings, thus mentioning of ARR and NNT while depicting data may be a better indicator for rational decision making.

Graphs are well recognized representation of the data. These communicate complex data with clarity, precision and efficiency and give the viewer much information in a short span.

According to the Tufte's design "principles" graphics should: ${ }^{12}$

- Maintain graphical integrity (do not lie)

- Maximize data density (show as much data as possible)

- Use multifunctional graphical elements (be creative)

- Maximize data-to-ink ratio

- Use small multiples

- Avoid chart junk

- Use colors with caution

- Increase data comprehension by providing legible labels, annotations, detail

- Do not use graphics when not necessary

Good graphics in general should be well-labeled, with appropriate legends, should have clearly labeled axis, define all symbols, and avoid numeric distortion. All these features help in better interpretation of data. No redundant text/tables with graphic were noted. We found that $24.5 \%$ of graphics had internal contradictions, and $4.5 \%$ had discrepancies between the graphic and text while axes were not labeled in $13.5 \%$ of graphics. Graphics should be simple and lucid for better understanding. But sometimes these are made to look complex by making extraneous lines, grids, colors, and 3D effects which are called "chart junks". These may be deliberately introduced to mask the truth of data and distort the findings while trying to make them impressive at a cursory glance. $54 \%$ of graphics had chart junks. ${ }^{12,23}$

DDI is an objective measurement that conveys the amount of information per area in a display chart or graphic, but it does not mention the amount of relevant data portrayed which is one of the limitations of our study. ${ }^{11}$ It was observed that there is lack of efficient use of space and ink to convey information. DDI was observed to be 0.14 , which is much lower than that seen in other studies. ${ }^{11}$ The reason could be use of simple univariate display of statistics in this sample which lowers the density.

Graphics should be precise and accurate; they should convey the true depiction of data. The measurement of graphic should be in proportion to the quantity. Lie factor is quantitative estimation of distortion in graphs. Lie factor is size of effect shown in graphic / size of effect shown in data. If lie factor is more than 1 , it signifies that the graphic effect is exaggerated. In our study, the lie factor was 6.56 (0.94-10.6) suggestive of over exaggeration of results by the advertisers.

A huge amount is spent on promotions which increases the health care cost. Thus a physician should be aware of flaws in such promotional activities before accepting their information brochure. This will help in better, 
vigilant and appropriate prescribing, and will ultimately prove beneficial for the patient. India has regional ethics committees to collect complaints against unethical drug promotion advertisements at Mumbai, New Delhi, Chennai, and Chandigarh. ${ }^{2}$ They forward these complaints to Drug Controller General of India, who then take legal steps. Appropriate \& legally binding guidelines will usher in an era of self regulation and adherence leading to ethical drug promotion thus helping to achieve the rational prescribing goals.

\section{CONCLUSION}

Drug promotion brochures are often relied upon by physicians looking for readily available information due to time constraint, especially, for newer drugs. The brochures analyzed by us were found to be unreliable and do not conform to the standard guidelines. Low percentage of adherence to the guidelines in study reflects commercial interest of pharmaceutical companies and weak educational aspect. There is need for regulatory agencies to go in for stricter vigilance of drug promotion brochures for proper dissemination of drug information as it affects the drug prescribing behaviour.

\section{Funding: No funding sources \\ Conflict of interest: None declared \\ Ethical approval: Not required}

\section{REFERENCES}

1. Mali SN, Dudhgaonka S, Bachewar NP. Evaluation of rationality of promotional drug literature using World Health Organization guidelines. Ind J Pharmacol. Oct 2010;42(5):267-72.

2. Levy R. The role and value of Pharmaceutical Marketing. Arch Fam Med. 1994;3:327-32.

3. Wind Y. Pharmaceutical advertising. A business school perspective. Arch Fam Med. 1994;3:321-3.

4. Lexchin J. Physicians and drug companies interact. Can Fam Physician. 1993;39:1881-2.

5. Charan J, Yadav P, Saxena D, Kantharia ND. Drug advertisements published in Indian Medical Journals: Are they ethical? J Pharm Bioallied Sci. 2011 JulSep;3(3):403-6.

6. WHO, 1988. Ethical Criteria for medicinal drug Promotion. Available from: http://apps.who.int/medicinedocs/documents/whozip08e /whozip08e.pdf.

7. Organization of Pharmaceutical Producers of India. OPPI code of pharmaceutical marketing practices 2012 . Available from: https://www.indiaoppi.com/sites/default/files/PDF\%20fi les/OPPI\%20Code\%20of\%20Pharmaceutical\%20Practi ces\%20\%20-\%202012_0.pdf

8. Gitanjali B, Shashindran CH, Tripathi KD, Sethuraman KR. Are drug advertisements in Indian edition BMJ unethical? Br Med J. 1997;315:459-60.

9. Ved JK, Jagtiani SS, Chitnis KA. Pharmaceutical Advertisements in Indian Scientific Journals: Analysis of Completeness of Information Content. Intern $\mathrm{J}$ Pharma Sci Res. 2010;1(9):366-70.

10. Cardarelli R, Licciardone JC, Taylor LG. A crosssectional evidence-based review of pharmaceutical promotional marketing brochures and their underlying studies: Is what they tell us important and true? BMC Fam Prac. 2006;7:13.

11. Cooper RJ, Schringer DL, Wallace RC, Mikulich VJ, Wilkes MS. The quality and quantity of scientific graphs in pharmaceutical advertisements. J Gen Intern Med. 2003;18:294-7.

12. Tufte ER. The visual display of quantitative information: Graphical Integrity. Cheshire, CT: Graphic press; 1983.

13. Cooper RJ, Schriger DL, Tashman DA. An evaluation of the graphical literacy of Annals of Emergency Medicine. Ann Emerg Med. January 2001;37:13-9.

14. Approved Drug Products with Therapeutic Equivalence Evaluations. U.S. Department of Health And Human Services, Food And Drug Administration. Available from:

http://www.fda.gov/downloads/Drugs/DevelopmentApp rovalProcess/UCM071436.pdf

15. List of drugs approved. Central Drugs Standard Control Organization of India. Available from: http://cdsco.nic.in/writereaddata/Drugs-approved-listdec-2015.pdf

16. Carandang ED, Moulds RF. Pharmaceutical Advertisements in Australian Medical Publications Have They Improved. Med J Aust. 1994;161:671-2.

17. Chirac P, Pikon A, Poinsignon Y, Vitry A. Drug Marketing in French-Speaking African Countries. Soc Sci Med. 1993;36:1541-3.

18. Vlassov V, Mansfield P, Lexchin J, Vlassova A. Do drug advertisements in Russian medical journals provide essential information for safe prescribing? West J Med. 2001;174:391-4.

19. Al-Aqeel SA, Al-Sabhan JF, Sultan NY. Analysis of written advertising material distributed through community pharmacies in Riyadh, Saudi Arabia. Pharm Pract. 2013 Jul-Sep;11(3):138-43.

20. Shetty VV, Karve AV. Promotional literature: How do we critically appraise? J Post Grad Med. 2008;54(3):217-25

21. Forrow L, Taylor WC, Arnold RM. Absolutely relative: how research results are summarized can affect treatment decisions. Am J Med. 1992;92:1214.

22. Naylor CD, Chen E, Strauss B. Measured enthusiasm: does the method of reporting trial results alter perceptions of therapeutic effectiveness? Ann Intern Med. 1992;117:916-21.

23. Interdisciplinary modeling and visualization. Tufte's design principles. Available from: http://vis.cs.pitt.edu/teaching/cs2620/lectures/L04_Tufte Design.pdf

Cite this article as: Singh NR, Randhawa GK, Kashyap R, Kaur G. A critical evaluation of information in drug promotional brochures for validity as per WHO criteria. Int J Basic Clin Pharmacol 2017;6:1477-81. 